\title{
Uitdijende financiële macht: de monetaire orde van de ECB
}

\author{
Rodrigo Fernandez, Reijer Hendrikse \& David Hollanders*
}

\section{Inleiding}

Sinds de eurocrisis in 2010 is de macht van de Europese Centrale Bank (ECB) manifest geworden. De ECB was bij het Verdrag van Maastricht al op afstand gezet van enige parlementaire controle en publieke verantwoording. En de ECB was al verwijderd van en verheven boven de uitvoerende macht van nationale staten - in tegenstelling tot de Amerikaanse Federal Reserve (Fed), dat een herkenbaar onderdeel is van de Amerikaanse staat. Maar wat de 'onafhankelijkheid' van de ECB in de praktijk vermag, concretiseerde zich eerst vanaf 2010. Toen zagen eurolanden met een hoge schuldenlast bij ontstentenis van een eigen centrale bank en geldpers geen alternatief dan de ECB te gehoorzamen om toegang te krijgen tot liquiditeitssteun. Op de lijst met landen die ECB-oekazes ontvingen en opvolgden, staan Ierland, Spanje, Italië, Cyprus en Griekenland. Het ECB-monopolie op de geldpers bleek een effectief drukmiddel om lidstaten binnen het ordoliberale Europese project te houden.

Europese monetaire integratie heeft geleid tot verlies van monetaire soevereiniteit. Dit is de eerste component van een veranderde machtsrelatie die door de financiële crisis geconsolideerd is en vergroot wordt. De andere is de groeiende invloed van kapitaalmarkten - oftewel grootbanken - op de ECB. Deze laatste machtsaccumulatie is het gevolg van de toegenomen interdependentie van centrale banken en financiële markten om monetair beleid vorm te geven. De ECB bepaalt weliswaar voorwaarden (in bijzonder de rente) waartegen private banken bij haar lenen, maar die private banken bepalen vervolgens of en hoe dit op de eurozone afgestemde renteniveau daadwerkelijk doorgegeven wordt aan bedrijven, staten en consumenten. Privaatbanken vormen het (enige) monetaire transmissiekanaal en zijn daarmee het unieke private verlengstuk van de quasipublieke ECB. Deze verwevenheid tussen publieke en private partijen wordt infrastructurele macht genoemd (Mann, 1984). Hiermee opereren centrale banken in een hybride krachtenveld: zij zijn niet alleen publiek representant in en toezichthouder van 'de' markt, maar ook de vertegenwoordigers van private financiële belangen binnen de staat (Vogl, 2018). Dit laatste blijkt ook uit - en wordt verder verstrekt door - de draaideur tussen de ECB en grootbanken. ECB-bestuurders hebben dikwijls voor private banken gewerkt en/of gaan daar later werken. Met de toenemende verwevenheid van staat en markt accumuleren private actoren naast financieel gewin ook politieke macht (Hendrikse, 2012; Braun, 2018).

* Dr. Rodrigo Fernandez is postdoc aan de KU Leuven en senior onderzoeker bij SOMO. Dr. Reijer Hendrikse is Postdoctoraal onderzoeker aan de Vrije Universiteit Brussel. Dr. David Hollanders is redactiesecretaris van Beleid en Maatschappij. 
In deze bijdrage bespreken wij de ontwikkeling van deze symbiotische relatie aan de hand van het monetaire beleidsinstrument kwantitatieve verruiming (KV) door de ECB. Het op grote schaal opkopen van financiële activa (staats- en bedrijfsobligaties) werd voor het eerst ingezet door de VS en later in Japan in de jaren negentig. Onder andere de ECB volgde later. Met de in 2012 ingezette KV heeft de ECB actief nieuwe marktstructuren vormgegeven en geïnstitutionaliseerd. Daarbij is niet zozeer de omvang van het opkoopbeleid van belang, als wel de gehanteerde instrumenten en voorwaarden. Door het opkoopbeleid is de ECB nu eigenaar van 33 procent van de waardevolste grondstof op kapitaalmarkten: staatsobligaties van lidstaten (met uitzondering van Griekenland, dat van KV uitgesloten werd). Deze obligaties vormen een belangrijk deel van het onderpand op voor financiële markten belangrijke repomarkten.

KV was bedoeld om de crisis te op korte termijn te beteugelen, maar heeft tegelijkertijd op de lange termijn de voorwaarden gecreëerd voor een volgende crisis. De financiële crisis bestond uit een te grote private schuldenlast en is nu met KV (tijdelijk) 'opgelost' door nog meer private schulden te creëren en door private schulden te transformeren in publieke schulden. Daarmee blijven enkel bezuinigen en lastenverzwaringen als handelingsperspectief open voor volksvertegenwoordigers. Landen hebben enkel toegang tot de opkoopprogramma's als zij akkoord zijn met austerity. Het adresseren van het onderliggende probleem, het schuldgedreven economische model, is hiermee verder weg dan vóór de crisis. Problemen van deze financialisering zijn het dalende aandeel aan lonen, dalende bedrijfsinvesteringen, stagnerende productiviteitsgroei, de slinkende belastingbijdrage van het grootbedrijf en als gevolg hiervan een schuldgedreven economisch model (Fernandez \& Hendrikse, 2015). In navolging van Streeck (2014) stellen we dat KV bestond uit het kopen van tijd om de crisis te beteugelen.

\section{De crisis en de nieuwe machtsmiddelen}

De crisis legde een grote trans-Atlantische verwevenheid bloot. Deze was gedurende twee decennia gegroeid in én door de Europese Unie (EU), die de groei van 'nationale kampioenen' bevorderde. Deze megabanken waren geconcentreerd in Noordwest-Europa en bestond bij het uitbreken van de crisis uit banken uit Duitsland (Deutsche Bank), Frankrijk (BNP Paribas), Nederland (ING) en België (Dexia). Deze banken leenden op grote schaal, via het wereldwijde schaduwbancaire stelsel, met name via zogenoemde repomarkten, in dollars (Bayoumi, 2017). Door het opdrogen van deze markten konden (Europese) banken niet meer aan dollars komen die ze nodig hadden om aan hun verplichtingen te voldoen. De belangrijkste maatregel om de crisis te bestrijden was dan ook openstelling door de Fed van een zogenaamde swap line, met de ECB, dat ongelimiteerd dollars kon lenen om de Europese systeembanken van dollars te voorzien en een acute solvabiliteitscrisis af te wenden. De Fed werd verschaffer van wereldwijde liquiditeit en verving hiermee de rol van het schaduwbanciare systeem. Tooze stelt: 
'The Fed was inserting itself into the very mechanisms of the market-based banking model. The relationship between the state, as represented by the central bank, and the financial markets was nakedly revealed. The Fed was not just any branch of government. It was the bankers' bank, and as the crisis intensified the money market reorganized itself accordingly, taking on the shape of spokes with de Fed as the hub.' (Tooze, 2018, 207)

De swap-afspraak van de Fed luidde een nieuw hoofdstuk in de internationale politieke economie van monetair beleid in. Vrijwel elk land met een grote financiële sector werd afhankelijk van de Fed voor dollars. Hiermee bezat de Fed een nieuwe geopolitieke machtsbron, omdat het unilateraal kon beslissen welke centrale banken voor haar swaps in aanmerking kwamen.

Vanwege de acute crisissituatie - het gevaar dat problemen in een relatief onbelangrijk land banken en landen in het centrum van het financiële kapitalisme zouden raken - politiseerde de Fed dit instrument waarschijnlijk minimaal. In eerste instantie kregen de centrale banken van vier landen/economieën ongelimiteerde toegang tot dollars (eurozone, Japan, Verenigd Koninkrijk en Zwitserland); dit werd in twee rondes uitgebreid naar veertien landen: de resterende EU, Australië, Nieuw-Zeeland, Singapore, Brazilië, Mexico en Zuid-Korea (Tooze, 2018, 641). De ECB zou later haar nieuwe machtsmiddelen (verschaffen of stopzetten van liquiditeit) die voortkwamen uit de crisis wel inzetten voor een politiek project (Blyth, 2013; Stiglitz, 2016). De opstelling van de ECB vis-à-vis onder meer Griekenland en Ierland, hieronder verder besproken, zou wel een nieuwe postdemocratische dimensie toevoegen aan het EU-project en de nieuwe rol van de ECB hierin blootleggen.

\section{Nieuwe rol centrale banken en de groeiende infrastructurele macht}

Vogl (2017) maakt plausibel dat centrale banken sinds hun zeventiende-eeuwse geboorte immer sterk verweven zijn met de soevereine macht van de staat. Door innige vervlechting met financiële markten, producten en technieken werd de macht van de staat verdiept, terwijl financiële markten konden uitdijen onder de welwillende vleugels van de staat. Gedurende de tweede helft van de twintigste eeuw zijn centrale banken in navolging van de Amerikaanse Fed en de Duitse Bundesbank wereldwijd ontkoppeld van politieke besluitvormingsprocessen en democratische controle, en werden zij effectief een 'vierde macht' binnen de trias politica van uitvoerende, wetgevende en rechterlijke macht van het liberale staatsbestel (Vogl, 2017). Zodoende verwierven centrale banken staatssoevereiniteit, die ingezet werd ten behoeve van de financiële sector.

Voor de supranationale ECB en het bijkomende stelsel van nationale satellieten (ESCB) is deze 'onafhankelijkheid' volledig en onomkeerbaar juridisch dichtgetimmerd in artikel 107 van het Verdrag van Maastricht. De ECB staat derhalve niet alleen voor de ontdemocratisering en denationalisatie van monetaire politiek, maar is feitelijk een niet-statelijk orgaan dat desondanks een grote mate van staatssoevereiniteit geniet en uitoefent. Tegelijkertijd is de ECB afhankelijk van 
financiële markten om haar beleid vorm te geven. Zodoende zijn centrale banken 'transformatoren van overheidsmacht, die hun onafhankelijkheid van de staat omzetten in een staatsafhankelijkheid van financiële markten' (Vogl, 2017, 131). Deze dynamiek wordt 'infrastructurele macht' genoemd (zie Mann, 1984), die tot stand komt via 'verwevenheden tussen specifieke financiële markten en publieke actoren, zoals ministeries van financiën en centrale banken, die beleid uitvoeren via transacties in die markten' (Braun, 2018, 1). Terwijl centrale banken monetair beleid sinds de jaren tachtig in toenemende mate via transacties met financiële markten vormgeven, genieten diezelfde financiële partijen in toenemende mate politieke macht. Braun geeft voorbeelden hoe de ECB sinds de crisis de zogenaamde repo- en securitisatiemarkten heeft vormgegeven. Waar laatstgenoemde markt een grote rol speelde in het ontstaan van de financiële crisis, en diverse nationale toezichthouders er mitsdien kritisch over waren, heeft de ECB eigenhandig de markt voor asset backed securities (ABS) weer opgetuigd middels het vanwege kwantitatieve verruiming aanpassen van onderpandeisen en wetgeving. Zodoende heeft de ECB de financiële markten actief en structureel ondersteund, om daarmee ook het eigen marktgedreven beleid te reproduceren.

\section{Geldschepping door centrale banken}

Een van de bronnen van de infrastructurele macht van de ECB is kwantitatieve verruiming. Onder andere hiermee verschaft de ECB sinds de crisis liquiditeit. Het KV-beleid is in beginsel niet anders dan het conventionele beleid van open market operations dat centrale banken gebruiken om de rente te beïnvloeden door middel van het aankopen van effecten. Het KV-beleid verschilt echter door de omvang, het semipermanente karakter van de aankoop (obligaties worden in principe niet meer verkocht), de beoogde doelen op langere termijn en het vastleggen van de operatie in een nieuw uitgebreid institutioneel raamwerk. De ECBbalans nam toe na 2008, met een piek in 2012, maar nam vervolgens af richting 2015. In dat jaar echter werd het KV-beleid gelanceerd en kwam er een stijging van de balansomvang met circa 2,5 biljoen euro in drie jaar tijd.

Dit toont dat bij KV de ECB (door haarzelf gecreëerd) geld ruilt voor obligaties in handen van private partijen. De ECB en de Zwitserse centrale bank (SNB) hebben een programma om bedrijfsobligaties te kopen (en de SNB ook aandelen). De Fed heeft ook op grote schaal verpakte hypotheken gekocht, maar het grootste deel van de groei van de balansen van centrale banken wereldwijd sinds 2008 bestaat uit staatschuld, overgekocht van banken en financiële instellingen.

$\mathrm{Na}$ het overkopen van relatief risicoluwe (staats)obligaties door de centrale bank van private partijen beschikken de laatste over liquide middelen. Het doel van deze operatie is - volgens de ECB althans - dan om banken en andere financiële intermediairs te bewegen tot zogenoemde portfolio rebalancing. Dit geschiedt als financiële instellingen met de liquide middelen risicovoller beleggen, waarmee meer risicodragend kapitaal beschikbaar komt. Deze verschuiving resulteert, 


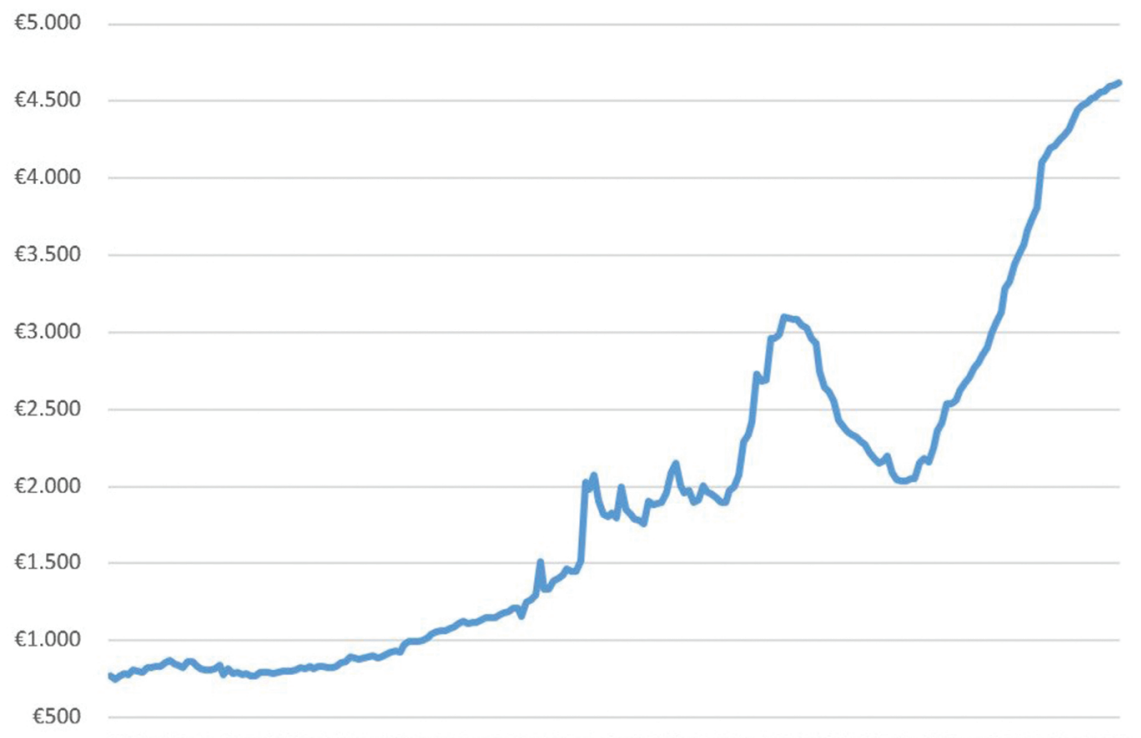

2000200120022003200420052006200720082009201020112012201320142015201620172018

(bron: FRED, https://fred.stlouisfed.org/series/ECBASSETS, geraadpleegd op 5 oktober 2018)

\section{Figuur 1 Balans van de ECB in miljarden euro's}

volgens de ECB, in meer (bedrijfs)investeringen en daarmee meer werkgelegenheid.

Wat daarvan ook zij, het beleid strekt tot voordeel van banken. Deze banken verkopen obligaties, gekocht van staten, aan de ECB, waarvan diezelfde staten weer aandeelhouder zijn. Diezelfde staten staan ook weer garant voor de banken, terwijl de initiële aanschaf van de obligaties gefinancierd was door leningen van de ECB (met diezelfde obligaties als onderpand). Kortom, banken zijn tussenpersoon tussen ECB en staten - en dus niet meer tussen min of meer private actoren en staten. Zij verdienen aan het renteverschil tussen in- en uitlenen en hebben in de ECB zowel een gegarandeerde financieringsbron als een gegarandeerde afnemer, waarmee zij kredietrisico noch liquiditeitsrisico lopen. KV is een geldmachine voor banken, vergelijkbaar met het in 2011 geïnitieerde leenprogramma LTRO (Long-Term Refinancing Operations), waarbij de ECB tegen looptijden tot drie jaar liquiditeit verschaft tegen een lage rente (1 procent). De banken konden het geleende geld weer uitlenen aan lidstaten tegen hogere renten. Buiter schat dat dit mechanisme tot een jaarlijkse subsidie heeft geleid van ongeveer 30 miljard euro per jaar. ${ }^{1}$

\section{Kwantitatief verruimen en het schuldgedreven accumulatieregime}

De beoogde macro-economische effecten van portfolio rebalancing - meer investeringen, meer werkgelegenheid en meer economische groei - waren vanaf het 
begin omstreden. De bank voor internationale betalingen zag geen relatie tussen de groei van de liquiditeit in het financiële systeem en macro-economische indicatoren (Borio \& Zabai, 2016; BIS, 2017b ). Voormalig president van de Fed Bernanke stelde ter verdediging van het QE-beleid: 'The problem with $\mathrm{QE}$ is that it works in practice, but it doesn't work in theory' (BIS, 2017a, 2).

Het is in ieder geval duidelijk dat de lange rente, die al drie decennia omlaag gaat, door KV nog verder naar beneden geduwd is. Hierdoor is geld lenen gestimuleerd. De prijzen van aandelen, vastgoed en overige financiële producten zijn explosief gestegen omdat een groeiende muur van geld op zoek is naar rendement. In het kielzog hiervan zijn ook risicovolle beleggingen, zoals met portfolio rebalancing ook beoogd, toegenomen, bijvoorbeeld obligaties uit opkomende landen (Fernandez e.a., 2018). Dit laatste betekent dat de liquiditeit die in het centrum van de wereldeconomie is geïnjecteerd zich middels mondiaal geïntegreerde kapitaalmarkten wereldwijd verspreidt.

Dit alles heeft meerdere, directe en indirecte gevolgen gehad. Ten eerste zijn de koersstijgingen van effecten en vastgoed bij een kleine groep terechtgekomen en heeft KV de vermogensongelijkheid daarmee versterkt. De ECB $(2017,48)$ laat zien dat als gevolg van haar monetair beleid tussen 2014 en 2016 de huishoudens in de eurozone die tot de hoogste 20 procent van de vermogensverdeling horen hun netto vermogen met 30 procent zagen stijgen ten opzichte van hun inkomen. Huishoudens die tot de laagste 40 procent behoorden in termen van vermogen zagen een stijging van 4 procent. De Duitse centrale bank laat zien dat de verdeling tussen de winnaars en verliezers tussen de verschillende eurolanden sterk uiteenloopt. Met name Nederland en Duitsland zagen de rente tot historisch lage waarden dalen, waarbij de rente bij uitgifte van nieuwe obligaties soms negatief was. In 2008-2017 hebben eurolanden gezamenlijk 1.000 miljard euro minder aan rente betaald; Duitsland had een profijt van 250 miljard euro (Deutsche Bundesbank, 2017, 1).

\section{Verdieping postdemocratisch bestel}

Het beleid van de ECB strekt tot voordeel van private banken en biedt weinig ruimte voor autonoom beleid van lidstaten. Over het contrast tussen bejegening van banken en staten stelde De Grauwe (2016): 'While the ECB showed much resistance to providing liquidity in government bond markets (...), it was happy to provide the necessary liquidity to banks. ${ }^{2}$ Inderdaad werden voor banken onderpandeisen versoepeld, werd de rente verlaagd, werd het leenvolume vergroot.

Het mag niet verbazen dat de ECB banken bevoordeelt. Terwijl de ECB geen verantwoording schuldig is aan nationale en Europese parlementen, zijn de personele en institutionele banden tussen de ECB en de financiële sector nauw. De 22 adviesgroepen van de ECB worden nagenoeg uitsluitend bemand door de financiële sector (508 van de 517 posities). ${ }^{3}$ Meerdere ECB-bestuurders gingen na hun bestuursperiode werken in de financiële sector. ${ }^{4}$ Ook tijdens hun bestuursperiode blijken bestuursleden in nauw contact te staan met bankiers. Zo ontmoetten 
bestuursleden Cœuré en Mersch USB-bankiers vlak voor een ECB-vergadering waarbij de ECB verraste met een renteverlaging. ${ }^{5}$ En onlangs bleek Draghi lid van bankiersclub G30; de Europese ombudsman O'Reilly stelde dat Draghi zijn lidmaatschap dient op te zeggen. ${ }^{6}$ Als bekend werkte Draghi vóór zijn presidentschap bij Goldman Sachs.

\section{Conclusie}

De grote financiële crisis van 2008 was op verschillende manieren een historisch scharnierpunt. Het toonde de mogelijkheid van een existentiële inzinking van het gefinancialiseerde kapitalisme en creëerde hiermee de mogelijkheid om angst effectief om te zetten in politiek kapitaal. Systeembanken, te groot om failliet te gaan, dwongen staten verliezen van banken te socialiseren. In deze context verwierven centrale banken nieuwe machtsmiddelen. Het project van de Europese monetaire integratie is altijd gepaard gegaan met een verlies van monetaire soevereiniteit, maar tot de eurocrisis was dat gegeven goeddeels abstract. De crisis heeft pijnlijk blootgelegd hoe de praktijk eruitziet als nationale staten geen eigen munt hebben. De afhankelijkheid van lidstaten van de geldpers en daarmee van de machtspositie van de ECB is onlosmakelijk verbonden met crises en het vermogen om angst politiek in te zetten.

Parallel aan dit proces werd de ECB in toenemende mate afhankelijk van financiële markten en actoren om haar beleid uit te voeren. Dit vergrootte de infrastructurele macht van de grootbanken, doordat zij onmisbaar zijn voor uitoefening van de taken van de ECB, zoals het opkopen van activa. De combinatie van beide ontwikkelingen - de structurele macht van de ECB ten opzichte van eurolidstaten en de infrastructurele macht van grootbanken - hebben de positie van financiële kapitaal vis-à-vis het electoraat versterkt.

Een fundamenteler probleem is dat KV het contemporaine kapitalistische accumulatieregime heeft verdiept. Het schuldgedreven model betekent dat een schuldencrisis (inkomens kunnen de schuldenlast niet meer dragen) tijdelijk is overwonnen door meer schulden te creëren. Schulden zijn een vordering op toekomstige inkomens en productie. Sinds 2008 zijn de schulden wereldwijd toegenomen met 90 biljoen, grofweg een verdubbeling sinds de financiële crisis (Mbaye \& Badia, 2019). Doordat de schuldtoename groter is dan de groei van de inkomens, is een schuldgedreven systeem per definitie niet duurzaam en lijkt een volgende crisis onvermijdelijk. De KV heeft tijd gekocht, maar geen openingen gecreëerd om los te komen van het schuldgedreven accumulatieregime. Het laat zich aanzien dat de infrastructurele macht van grootbanken enkel gebroken kan worden door en na terugwinnen van democratische controle. Dit vraagt om een breder maatschappelijk debat en een einde aan de notie dat de monetaire orde een technische aangelegenheid is. Het is dit idee dat de invloed van het electoraal op de monetaire autoriteit mogelijk heeft gemaakt. 


\section{Noten}

1 Buiter. W. (2014). Central banks: Powerful, Political and Unaccountable? (MPRA Paper, nr. 59477), 13.

2 De Grauwe $(2016,173)$.

3 Dietsch, Claveau \& Fontan (2018).

4 Braun (2017) noemt oud-ECB-bestuurders Padoa-Schioppa, Issing, Gonzalez Paramo, Bini Smaghi en Asmussen.

5 Jones, C. (2015, 2 november). ECB officials met bankers before key decisions. Financial Times . ft.com/content/7a9d5d9a-8155-11e5-a01c-8650859a4767. Maart 2015 ontmoette Cœuré Blackrock-medewerkers één dag vóór de openbaarmaking van de details van Kwantitatieve verruiming. Andere bestuursleden ontmoetten onder anderen Pimco, een grote obligatiehandelaar en direct belanghebbende bij elke ECB-beslissing. Eerder stelde Cœuré de financiële sector in kennis van niet-openbare informatie. De ECB noemde dat later een 'internal procedural error'.

6 Boffey, D. (2018, 17 januari). Mario Draghi told to drop membership of secretive bankers' club. The Guardian. theguardian.com/business/2018/jan/17/mario-draghi-ecbdrop-membership-secretive-bankers-g30-club.

\section{Literatuur}

Bayoumi, T. (2017). Unfinished Business: The unexplored causes of the financial crisis and the lessons yet to be learned. New Haven and Londen: Yale University Press.

BIS (2017a). QE experiences and some lessons for monetary policy: defending the important role central banks have played (The Eurofi High Level Seminar 2017, Malta). Beschikbaar via www.bis.org/speeches/sp170407.pdf.

BIS (2017b). Market volatility, monetary policy and the term premium (BIS Working Papers, $\mathrm{nr}, 606)$. Bazel.

Blyth, M. (2013). Austerity: The history of a dangerous idea. Oxford: Oxford University Press.

Borio, C., \& Zabai, A. (2016). Unconventional monetary policies: a re-appraisal (BIS Working Papers, nr. 570). Monetary and Economic Department.

Braun, B. (2018). Central banking and the infrastructural power of finance: The case of the ECB support for repo and securitization markets. Socio-Economic Review. https://doi. org/10.1093/ser/mwy008.

Deutsche Bundesbank (2017). The development of government interest expenditure in Germany and other euro-area countries. Deutsche Bundesbank Monthly Report, juli. www.bundesbank.de/Redaktion/EN/Downloads/Publications/.

Dietsch, P., Claveau, F., \& Fontan, C. (2018). Do central banks serve the people? Polity.

ECB (2017). Annual report 2016. Frankfurt.

Fernandez, R., and Hendrikse, R. (2015). Rich corporations, poor societies: The financialisation of Apple. Amsterdam: SOMO report. https://www.somo.nl/wp-content/ uploads/2015/10/Rich-corporations-poor-societies.pdf, geraadpleegd op 12 maart 2019.

Fernandez, R., Bortz, P and Zeolla, N (2018). The politics of quantitative easing: A critical assesment of the harmful impact of European monetary policy on developing coun- 
tries. Amsterdam: SOMO report. https://www.somo.nl/wp-content/uploads/ 2018/06/Report-Quantitive-Easing-web.pdf, geraadpleegd op 12 maart 2019. Grauwe, P. de (2016). Economics of Monetary Union. Oxford University Press.

Hendrikse, R.P. (2012). De financialisering van Europa. Agora Magazine, 3: 16-20. Hollanders, D.A. (2018). Wie de geldpers controleert, is soeverein. Lava, 06: 83-97. Mann, T. (1984). The autonomous power of the state: Its origins, mechanisms and results. European Journal of Sociology, 25: 185-213.

Mbaye, S. and Badia, M. (2019). New data on Global Debt. IMF blog. Washington IMF: https://blogs.imf.org/2019/01/02/new-data-on-global-debt/, geraadpleegd op 12 maart 2019.

Monthly_Report_Articles/2017/2017_07_development.pdf?_blob=publicationFile.

Piketty, T. (2014). Capital in the 21st Century. Harvard University Press.

Stiglitz, J. (2016). The Euro: how a common currency threatens the future of Europe. New York and London: W.W. Norton \& Company.

Streeck, W. (2014). How Will Capitalism End? Essays on a Failing System. Brooklyn, NY: Verso Books.

Streeck, W. (2018). The Fourth Power. New Left Review, maart-april: 141-150.

Tuner, A. (2015). Between Debt and the Devil: Money, Credit, and Fixing Global Finance. Princeton University Press.

Vogl, J. (2017). The Ascendancy of Finance. Londen: Polity Press.

Woodruff, M. (2014). Governing by Panic: The Politics of the Eurozone Crisis (LSE 'Europe in Question' Discussion Paper Series, nr. 81). 